\title{
The relationship between climate and the intra-annual oxygen isotope patterns from pine trees: a case study along an elevation gradient on Corsica, France
}

\author{
Sonja Szymczak ${ }^{1}$ (D) - Achim Bräuning ${ }^{1} \cdot$ Martin Häusser $^{1} \cdot$ Emilie Garel $^{2,3} \cdot$ Frédéric Huneau $^{2,3} \cdot$ Sébastien Santoni ${ }^{2,3}$
}

Received: 7 February 2019 / Accepted: 8 July 2019 / Published online: 29 July 2019

(C) INRA and Springer-Verlag France SAS, part of Springer Nature 2019

\begin{abstract}
- Key message Intra-annual oxygen isotope patterns of tree-ring cellulose from Pinus nigra subsp. laricio and Pinus pinaster along an elevation gradient can be divided into four distinct patterns ((1) high values in the beginning of the tree ring, declining trend afterwards; (2) low values in the beginning, increasing trend afterwards; (3) high values in the middle of the tree ring; (4) declining trend over the whole tree ring). These patterns reflect the dependency on local site conditions and different water sources.

- Context Intra-annual oxygen isotope chronologies from tree-ring cellulose can serve as a proxy for past climate conditions at inter- or even intra-seasonal resolution.

- Aims We explore the potential of these chronologies from pine trees (Pinus nigra J.F. Arn subsp. laricio (Poiret) Maire var Corsicana Hyl. and Pinus pinaster Aiton) growing on the Mediterranean island of Corsica, France, along an elevation gradient ranging from sea level to $1600 \mathrm{~m}$ asl.

- Methods We developed high-resolution intra-annual oxygen isotope chronologies from tree-ring cellulose of eight trees from five sites along the elevation gradient. The analysis period covers the decade 2007-2016 for seven trees and the period 19872016 for one tree, respectively.

- Results The chronologies show a high variability between trees, sites, and years. We identified four different intra-annual oxygen isotope patterns which reflect the dependency of tree growth on different water sources (precipitation during the growing season vs. deeper soil water reservoirs) and climate conditions during the growth season. Trees at coastal sites have access to groundwater, while trees growing in high elevations mostly depend on precipitation during the growth season as water source. - Conclusion The different patterns can be attributed to the use of different water sources. The intra-annual chronology covering 30 years indicates an increasing frequency of dry-warm summers after 2007.
\end{abstract}

Keywords Oxygen isotopes $\cdot$ Pinus nigra $\cdot$ Pinus pinaster $\cdot$ Intra-annual $\cdot$ Elevation gradient $\cdot$ Mediterranean

Handling Editor: Erwin Dreyer

Contribution of the co-authors

$\mathrm{SSz}$ and $\mathrm{AB}$ conceived the ideas; $\mathrm{SSz}, \mathrm{AB}, \mathrm{MH}, \mathrm{EG}, \mathrm{FH}$, and $\mathrm{SSa}$ enabled and conducted the fieldwork; $\mathrm{SSz}$ and $\mathrm{MH}$ analyzed the data; $\mathrm{SSz}$ led the writing with assistance from $\mathrm{AB}, \mathrm{MH}, \mathrm{EG}, \mathrm{FH}$, and $\mathrm{SSa}$.

Sonja Szymczak

sonja.szymczak@fau.de

1 Institute of Geography, Friedrich-Alexander-University Erlangen-Nürnberg, Wetterkreuz 15, 91058 Erlangen, Germany

2 Laboratoire d'Hydrogéologie, Faculté des Sciences et Techniques, Université de Corse Pascal Paoli, Campus Grimaldi, BP 52, F-20250 Corte, France

3 CNRS, UMR 6134, SPE, F-20250 Corte, France

\section{Introduction}

Stable isotopes are an essential tool in palaeoclimatology because they can be measured in a large variety of natural archives (e.g., trees, speleothems, lake sediments, ice cores) and allow the reconstruction of different climatic parameters and processes in different environments, for different time scales, and with different temporal resolutions. Most frequently, the isotope ratios of carbon and oxygen are measured since these isotopes can contain information not only about palaeoclimate, but also about important metabolic cycles (e.g., water or carbon cycle). In contrast to isotope time series from other archives, isotope chronologies from tree-ring cellulose provide precisely dated annual or even subseasonal records with up to monthly or even 
weekly temporal resolution, when tree-ring samples are analyzed at intra-annual spatial resolution (e.g., Evans and Schrag 2004; Szejner et al. 2018).

Oxygen isotope ratios in tree rings are influenced by several factors which makes it difficult to extract a single parameter determining the measured isotope signal (McCarroll and Loader 2004). The oxygen isotope value in tree rings depends on the isotopic signature of the source water, fractionation processes in leaf water during transpiration, biochemical fractionation during biosynthesis, and ${ }^{18} \mathrm{O} /{ }^{16} \mathrm{O}$ exchange reactions between xylem water and phloem concentrate (Barbour et al. 2002; Helle and Schleser 2004; Roden et al. 2000). For a robust climatic interpretation of oxygen isotope values in tree-ring cellulose (thereafter $\delta^{18} \mathrm{O}_{\mathrm{TRC}}$ ), it is therefore important to know to which degree the isotope signal is determined by the isotopic signature of the source water, and to which extent it is modified through post-photosynthetic processes (Offermann et al. 2011). However, the contribution of each process is often ambiguous and depends on study site and tree species. Despite this complexity, $\delta^{18} \mathrm{O}_{\mathrm{TRC}}$ has been applied for the reconstruction of different atmospheric parameters like the isotopic signature of precipitation (e.g., Danis et al. 2006; Robertson et al. 2001), air temperature (e.g., Edwards et al. 2008), amount of precipitation (e.g., Grießinger et al. 2011; Reynolds-Henne et al. 2007; Treydte et al. 2007), relative air humidity (e.g., Edwards et al. 2008; Wernicke et al. 2015), cloud cover (Liu et al. 2012), and atmospheric circulation patterns (e.g., Brienen et al. 2012; Liu et al. 2012; Saurer et al. 2012; Wernicke et al. 2016). The high diversity of reconstructable climate parameters mirrors the complexity of $\delta^{18} \mathrm{O}_{\mathrm{TRC}}$ signals in different environments.

A deeper understanding of the relationship between climate and oxygen isotopes can be obtained by the development of intra-annual isotope chronologies. Although the approach is laborious, such high-resolution dendro-isotope analyses are useful for obtaining information at seasonal or even weekly time resolution, i.e., growth season changes in water availability and humidity (e.g., Jahren and Sternberg 2003; Verheyden et al. 2004) or seasonal changes in moisture source (Miller et al. 2006). Since climate change is characterized not only by change in the long-term means of climate during the growth season, but also by the occurrence of climatic extremes, intra-annual isotope chronologies can provide information about the timing, frequency, and magnitude of such extremes, e.g., the occurrence of heavy storms (e.g., Li et al. 2011; Poussart et al. 2004). In tropical trees, where wood anatomically determined growth bands are not necessarily of annual nature, the development of intra-annual isotope chronologies can be useful in dating growth rings of tree species without annually formed ring boundaries (e.g., Evans and Schrag 2004; Poussart et al. 2006). Additionally, besides carrying climatic information, intra-annual isotope chronologies can serve as indicators for seasonal changes in water-use efficiency and photosynthetic regulations (Barbour et al. 2002; Gessler et al. 2009; Helle and Schleser 2004; Klein et al. 2005).

According to previous studies using intra-annual isotope chronologies developed from different tree species growing in a broad range of climate conditions (see Schubert and Jahren (2015) for an overview), no universal pattern of intraannual isotope variability exists. More specifically, these studies have shown a large variability of intra-annual patterns (Reynolds-Henne et al. 2007; Richter et al. 2008; Roden et al. 2009; Wang et al. 1998). This implies that the interpretation of intra-annual isotope variability depends on the studied species, regional climate, and local meteorology (Berkelhammer and Stott 2009).

Here, we present 10-year long intra-annual oxygen isotope chronologies from trees of two different pine species (Pinus nigra J.F. Arn. subsp. laricio (Poiret) Maire var Corsicana Hyl. and Pinus pinaster Aiton) growing along an elevation gradient $(0-1600 \mathrm{~m}$ asl) at five different sites on the French island of Corsica in the Western Mediterranean basin. The main objectives of the study were (i) to determine how $\delta^{18} \mathrm{O}_{\mathrm{TRC}}$ in pine trees fluctuates throughout the growing season and (ii) to test if similarities of seasonal isotope variations exist between sites and trees of a site. In addition, we (iii) hypothesized that characteristic intra-annual stable isotope patterns depend on the climate conditions during the vegetation period. For one site, we prolonged the chronology to 30 years, which allows a robust statistical analysis of the occurrence of different isotope patterns and the evolution of such patterns under changing climate conditions.

\section{Material and methods}

\subsection{Study sites}

Corsica, with an area of $8652 \mathrm{~km}^{2}$, is located between $41-43^{\circ}$ $\mathrm{N}$ and $8-10^{\circ} \mathrm{E}$ and is characterized by a rugged mountainous topography with a mountain range that consists of several massifs of Variscan origin (e.g., Monte Cinto with $2706 \mathrm{~m}$ asl and Monte Renoso with $2352 \mathrm{~m}$ asl). Due to the steep elevation gradient, Corsica hosts different microclimates within a distance of only a few kilometers, ranging from a typical Mediterranean climate with dry-warm summers and temperate wet winters to alpine conditions in the high mountain areas, with a winter snow cover above $1500 \mathrm{~m}$ asl. Corsican vegetation is very diverse and characterized by Mediterranean as well as alpine floral elements. The lowland forests are dominated by typical Mediterranean tree species such as maritime pine (Pinus pinaster), holm oak (Quercus ilex L.), pubescent oak (Quercus pubescens Willd.), cork oak (Quercus suber L.), and sweet chestnut (Castanea sativa Mill.). The mountainous 
forest belt following in elevations between 1000 and $1800 \mathrm{~m}$ asl mainly consists of Corsican pine (Pinus nigra ssp. laricio).

To cover the full range of different ecological conditions, our study sites are aligned along an east-west transect from coast to coast, crossing the Renoso massif in central Corsica (Fig. 1, Table 1). We selected five sites for the development of intra-annual $\delta^{18} \mathrm{O}_{\mathrm{TRC}}$ chronologies. Ajaccio and Ghisonaccia are small forest patches of Pinus pinaster stands at sea level, located at the west (Ajaccio) and east (Ghisonaccia) coast, respectively. The soils are well-developed Cambisols (Ajaccio) and podzols (Ghisonaccia) on sandy alluvial deposits. Bocognano (west of the main mountain range) and Vivario (east of the main mountain range), the mid-elevation sites, are located within the mountain forest belt where both pine species occur. Soils are Cambisols of varying depth on bare granite. Capannelle is located at the upper timber line on the east slopes of Monte Renoso. The open forest consists of old-grown Pinus nigra ssp. laricio and Fagus sylvatica L. trees. The soil is a shallow podzolic Cambisol on bare granite with low water-holding capacity.

\subsection{Climate characteristics of the study sites}

Long-term climate records are only available for some of the study sites. We chose the nearest and from the topographical positions most representative climate stations from the Météo France network (Météo France 2018) based on the calculation of correlation factors between the stations and our own climate stations set up in April 2017. The location of the Météo France climate stations is shown in Fig. 1. Temperatures were adjusted to the altitude of the study sites by using a humid adiabatic gradient between 0.5 and $0.6{ }^{\circ} \mathrm{C} / 100 \mathrm{~m}$, depending on the mean temperature difference between our own climate station and the nearest Météo France climate station. This was necessary because the highest available climate station is located at $1000 \mathrm{~m}$ asl. Because of the high spatial variability of precipitation on Corsica (Bruno et al. 2001), no correction factors were applied to precipitation data; therefore, the precipitation amounts for the mountain stations are probably underestimated. Air humidity measurements are only available for the two coastal locations and one mid-elevation station. Data are reported as mean values for the time period 2007-2016, i.e., the years covered by the isotope chronologies.

Mean annual temperature along the studied transect ranges between $7.4{ }^{\circ} \mathrm{C}$ (Capannelle) and $16.9{ }^{\circ} \mathrm{C}$ (Ghisonaccia). Temperature shows a clear elevation gradient with a lapse rate of $0.6{ }^{\circ} \mathrm{C} / 100 \mathrm{~m}$ between the coastal and the highest sites; however, the mid-elevation site Bocognano is only slightly warmer than Vivario, although Vivario is $210 \mathrm{~m}$ higher. The

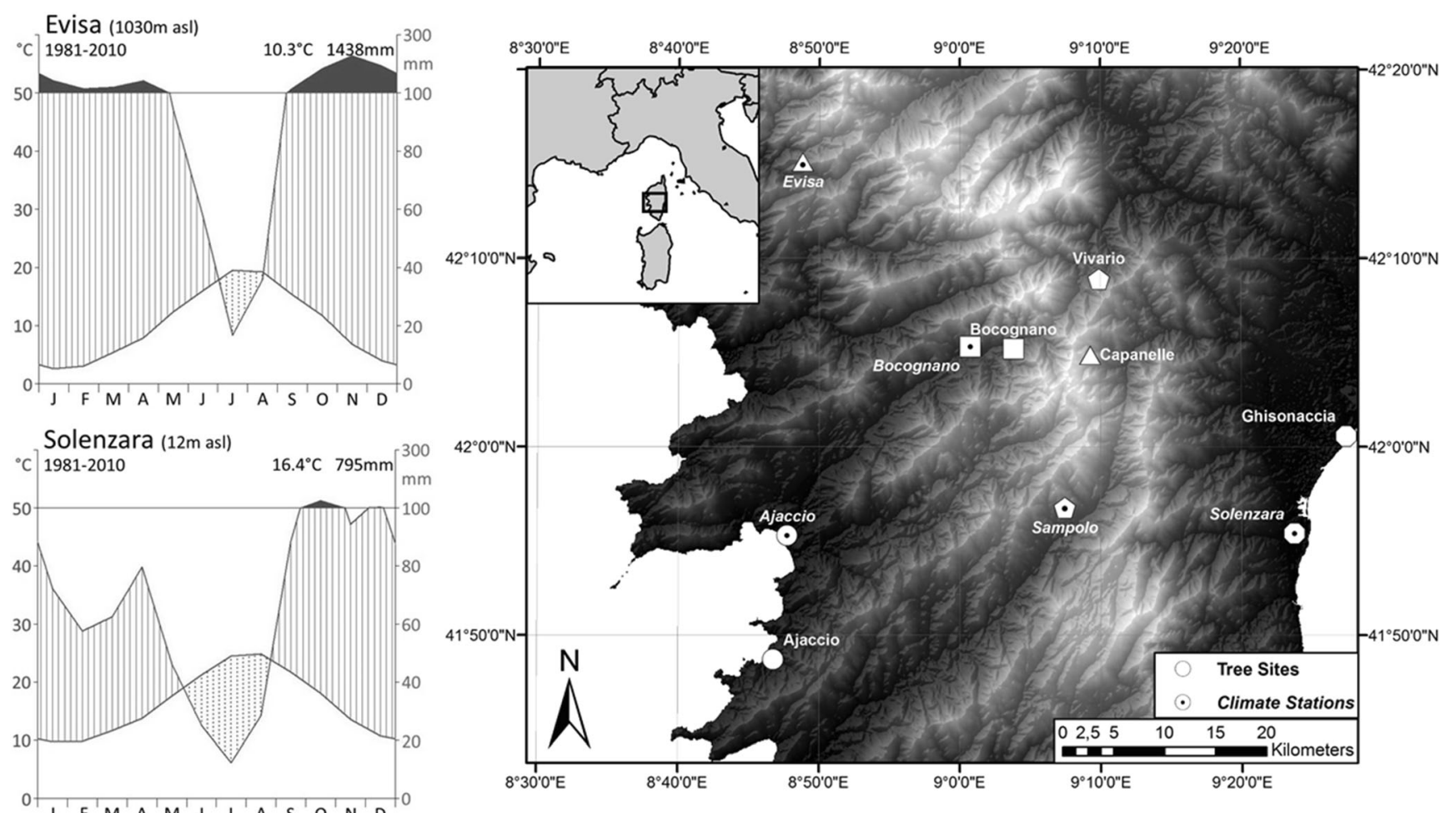

Fig. 1 Map showing the location of the study sites (white symbols) and Météo France climate stations (symbols with black dots). Each tree site and the corresponding most representative climate station are marked with the same symbol. The climate diagrams are from the highest (Evisa) and one of the coastal Météo France climate stations to underline the climatic differences between the study sites. Ecological climate diagrams after Walter/Lieth were created with the R-package climatol (Guijarro, 2018; R Core Team, 2019) with climate data from Météo France (2018). Digital elevation model is based on SRTM data (USGS 2018) 
Table 1 Characteristics of the study sites and isotope measurements from eight trees (Pinus nigra ssp. laricio (PINI) and Pinus pinaster (PIPI)). The trees are numbered (one or two trees per site) and named after their location (AJ, Ajaccio; BO, Bocognano; CA, Capannelle; GI, Ghisonaccia; VI, Vivario)

\begin{tabular}{|c|c|c|c|c|c|c|c|c|c|}
\hline \multirow[t]{2}{*}{ Tree ID } & \multirow[t]{2}{*}{ Coordinates } & \multirow{2}{*}{$\begin{array}{l}\text { Elevation } \\
(\mathrm{m} \text { asl) }\end{array}$} & \multirow[t]{2}{*}{ Tree species } & \multirow{2}{*}{$\begin{array}{l}\text { Tree age } \\
\text { (in 2016) }\end{array}$} & \multicolumn{2}{|c|}{ Number of samples per ring } & \multicolumn{3}{|c|}{$\delta^{18} \mathrm{O}$ values $(\% o)$} \\
\hline & & & & & Min & Max & Mean & Min & Max \\
\hline AJ_1 & $41.81,8.78$ & 15 & PIPI & 35 & 5 & 15 & 30.95 & 27.02 & 33.76 \\
\hline BO_1 & $42.09,9.08$ & 790 & PINI & 28 & 5 & 20 & 32.58 & 30.71 & 34.95 \\
\hline BO_2 & $42.09,9.08$ & 790 & PIPI & 38 & 5 & 10 & 32.12 & 29.71 & 34.97 \\
\hline CA_1 & $42.08,9.16$ & 1600 & PINI & 65 & 10 & 15 & 32.66 & 30.39 & 35.23 \\
\hline CA_2 & $42.08,9.16$ & 1600 & PINI & 60 & 5 & 20 & 31.31 & 29.28 & 33.33 \\
\hline GI_1 & $42.02,9.46$ & 10 & PIPI & 24 & 15 & 20 & 31.77 & 28.46 & 34.01 \\
\hline VI_1 & $42.15,9.17$ & 1000 & PINI & 27 & 10 & 20 & 32.37 & 28.09 & 36.11 \\
\hline VI_2 & $42.15,9.17$ & 1000 & PIPI & 22 & 10 & 20 & 31.92 & 27.64 & 36.88 \\
\hline
\end{tabular}

east coast is warmer than the west coast. The difference of mean temperatures between the sites is largest in winter (DJF) and lowest in summer (JJA). Mean annual precipitation sums range between $699 \mathrm{~mm}$ (Ajaccio) and $1600.2 \mathrm{~mm}$ (Capannelle). The west coast is drier than the east coast, while at mid-elevations, the western site is wetter than the eastern site, despite its lower elevation. This difference can be explained by the local topography, since Bocognano is located in the wide-open Gravona valley, where air masses from the west coast can easily introduce into the interior of the island, frequently causing orographic rainfall. In contrast, site Vivario is protected against air masses from the east coast by a lower mountain range in the east. Differences in precipitation sums between sites are largest in DJF and lowest in JJA, when precipitation events by convective thunderstorms prevail. Precipitation is very unevenly distributed over the year. Periods without any rainfall mainly occur in summer and can last on average between 42 (Ajaccio) and 7 (Capannelle) days. Mean annual relative humidity ranges between $74 \%$ (Ajaccio) and 68\% (climate station Sampolo).

The beginning of the growth season is defined as the first day after the last 5-day period in spring with temperatures below $5{ }^{\circ} \mathrm{C}$, the end of the growth season is the last day in autumn before the first 5-day period with temperatures below $5{ }^{\circ} \mathrm{C}$ (Formayer et al. 2007). Based on this criterion, the duration of the growth season could not be determined for the coastal locations, since it would last for 365 days. However, first results from dendrometer data and wood anatomical analyses of microcores indicate the occurrence of a cambial dormancy period, and a beginning of tree growth in January/ February, with a termination of cambial activity in December (Häusser et al. 2019a). With increasing elevation, the length of the growth season is steadily decreasing from 281 days at Bocognano (from the beginning of March until the beginning of December) to 254 days at Vivario (from the beginning of March until the mid of November) to only 203 days at Capannelle (from the middle of April until the beginning of November).

\subsection{Development of intra-annual oxygen isotope chronologies}

At each site, we chose one or two trees for the development of intra-annual oxygen isotope chronologies, resulting in a total number of eight trees (four $P$. nigra and four $P$. pinaster) (Table 1). At sites where both pine species occur (Bocognano and Vivario), we selected one tree of each species. Additionally, we selected two trees of the same species (P. nigra) at one site (Capannelle). As a high resolution of the intra-annual chronologies was desirable, the most important criterion to select the study trees was the width of the tree rings. Additionally, the tree-ring width series of the target trees should correlate well with the local site chronologies. Treering width chronologies were developed for each site based on at least 17 trees (Häusser et al. 2019b). Another selection criterion was straight-line boundaries between consecutive tree rings to allow an accurate separation of isotope samples. As the growth conditions and stand structures vary strongly between the sites and hence the widths of the tree rings, it was not possible to select trees of similar ages. The age of the sampled trees ranged between 22 (Vivario) and 65 years (Capannelle) (Table 1). We selected the consecutive rings of the years 2007-2016 from each tree for intra-annual oxygen isotope measurements. Additionally, we prolonged the chronology from one tree (CA_1) to 30 years (1987-2016) for a robust statistical analysis of the occurrence of different average intra-annual isotope patterns resulting from differing climate conditions. In total, isotope patterns were developed from 100 tree rings. Tree rings were cut by hand using a razor blade. The highest amount of samples per tree ring was 20 . For better comparison between rings of different widths, tree rings were separated in either $5,10,15$, or 20 samples. 
Alpha-cellulose was extracted from each sample prior to isotope analyses. Cellulose extraction is an important prerequisite for the development of oxygen isotope series from $P$. nigra from Corsica (Szymczak et al. 2011). Especially for high-resolution analysis, the isotopic homogeneity and the fact that the isotopic composition represents the specific time at which it was produced are of great importance (Poussart et al. 2004). Cellulose extraction was conducted by using the Multiple Samples Isolation Systems according to Wieloch et al. (2011) and included delignification with acidified sodium chlorite solution (7\%) and alkaline hydrolysis with sodium hydroxide (5\% and 17\%). The alkaline hydrolysis was conducted twice, first to extract resin, fatty acids, and etheric oils (solution of 5\%), and second after delignification to extract hemicellulose (solution of 17\%). For oxygen isotope analysis, samples were weighed into silver capsules. Oxygen isotope ratios were measured using an elemental analyzer coupled to a Delta V Advantage IRMS (Thermo Fisher) while laboratory standards were periodically interposed to test analytical precision. Isotopic compositions were reported in permil using the conventional $\delta$ notation relative to VSMOW standard (Vienna Surface Mean Ocean Water). The analytical error was within typically reported analytical precisions $\left(\delta^{18} \mathrm{O}= \pm 0.3 \%\right.$ ) .

Tree rings of different widths allowed different sampling resolutions for isotope analyses. For better comparison of isotope patterns of tree rings of different widths, the values in years with a sample resolution less than 20 were distributed over 20 relative positions within the tree ring with equal distances between adjacent values (see Fig. 2). Missing values for the positions between adjacent values were calculated by linear interpolation. We compared the mean isotope pattern of each tree as well as the isotope pattern of each tree ring with the 99 isotope patterns of all other trees. For better comparison, each intra-annual isotope pattern was z-transformed in a first step. Afterwards, Pearson's correlation values were calculated between every intra-annual isotope pattern. The resulting correlation matrix was used as input data for a cluster analysis in order to group tree rings with similar isotope patterns together. The cluster analysis was conducted with the $\mathrm{R}$ Stats package and the package vegan as a hierarchical clustering method after Ward with Euclidian dissimilarities (Oksanen 2018; R Core Team 2009, 2019).

\subsection{Calculation of climate-isotope relationships}

The climate-isotope relationship was calculated between the mean intra-annual isotope patterns for each tree with the climate parameters mean temperature, precipitation sum, air humidity, and $\delta^{18} \mathrm{O}$ values of precipitation. All parameters except $\delta^{18} \mathrm{O}$ values of precipitation were taken from Météo France climate stations. The $\delta^{18} \mathrm{O}$ values of precipitation are from four stations of an island-wide network of precipitation collectors close to the studied transect. However, they only cover the time period 2014-2016. As climate input, we used monthly values from the months of the growth season. For the 30-year stable isotope chronology from tree CA 1, we identified four different mean intra-annual isotope patterns and calculated the relationship between these patterns and climate parameters.

\section{Results}

\subsection{Major features of the intra-annual oxygen isotope chronologies 2007-2016}

The intra-annual oxygen isotope chronologies showed a high variability of isotope patterns between sites, trees, and within trees between the years (Fig. 2, Table 2). The highest similarities occurred between the chronologies from trees at Capannelle $(r=0.52)$ and the $P$. pinaster trees from Bocognano and Vivario $(r=0.54)$. The chronologies of both trees at Vivario were significantly correlated $(r=0.36)$, while this was not the case for chronologies from trees at Bocognano. The chronologies of both coastal trees were also significantly correlated $(r=0.31)$. The mean $\delta^{18} \mathrm{O}_{\mathrm{TRC}}$ over the complete time period was lowest for AJ_1 and highest for CA_1 (Table 1). Trees at mid-elevation sites had a higher mean $\delta^{18} \mathrm{O}_{\mathrm{TRC}}$ than trees at coastal locations. The difference between mean $\delta^{18} \mathrm{O}_{\text {TRC }}$ from trees from one site was the highest at Capannelle, with CA_2 having considerable lower mean values than CA_1. The within-tree range of $\delta^{18} \mathrm{O}_{\mathrm{TRC}}$ was at least $4.05 \%$ (CA_2) with maximum differences of up to $9.24 \%$ (VI_2). Even within a year, the spread of $\delta^{18} \mathrm{O}_{\mathrm{TRC}}$ values was very high, ranging from $3.26 \%$ (CA_2) to $6.86 \%$ o (VI 2). In general, the range was higher in trees with a higher sample resolution. By comparing the mean isotope patterns of the individual trees, three different patterns could be distinguished (Fig. 5): BO_1, CA_1 and CA_2 started with low $\delta^{18} \mathrm{O}_{\mathrm{TRC}}$ values in the earlywood, followed by a steep increase to maximum values in the middle of the tree ring, and a declining trend afterwards. The pattern from AJ_1 and GI_1 was opposite, with highest $\delta^{18} \mathrm{O}_{\text {TRC }}$ values at the beginning and at the end of the tree ring, and low values in the center. The mean isotope pattern of the trees BO_2, VI_1 and VI_2 was characterized by a nearly continuously decreasing trend over the whole tree ring.

The cluster analysis (see Fig. 6 in the Appendix) identified four distinct isotope patterns, where isotope patterns 1 and 4 were furthest apart and isotope patterns 3 and 4 were most similar (Fig. 4a). Isotope pattern 4 was the most common pattern, with an occurrence of 41 times and a distribution over all sites. This pattern was characterized by a maximum $\delta^{18} \mathrm{O}_{\text {TRC }}$ in the first part of the tree ring and declining values afterwards, with a minimum at position 15 . It was opposite to isotope pattern 1 (occurring 17 times) which was 
Fig. 2 Intra-annual oxygen isotope chronologies for the years 2007-2016 from eight trees growing at five different locations along an elevation transect (site abbreviations: AJ, Ajaccio; GI, Ghisonaccia; BO, Bocognano; VI, Vivario; CA, Capannelle). Note that the number of measurements varies between years and trees due to varying tree-ring width. For better comparison, each year was distributed over 20 relative positions within each ring with equal distances

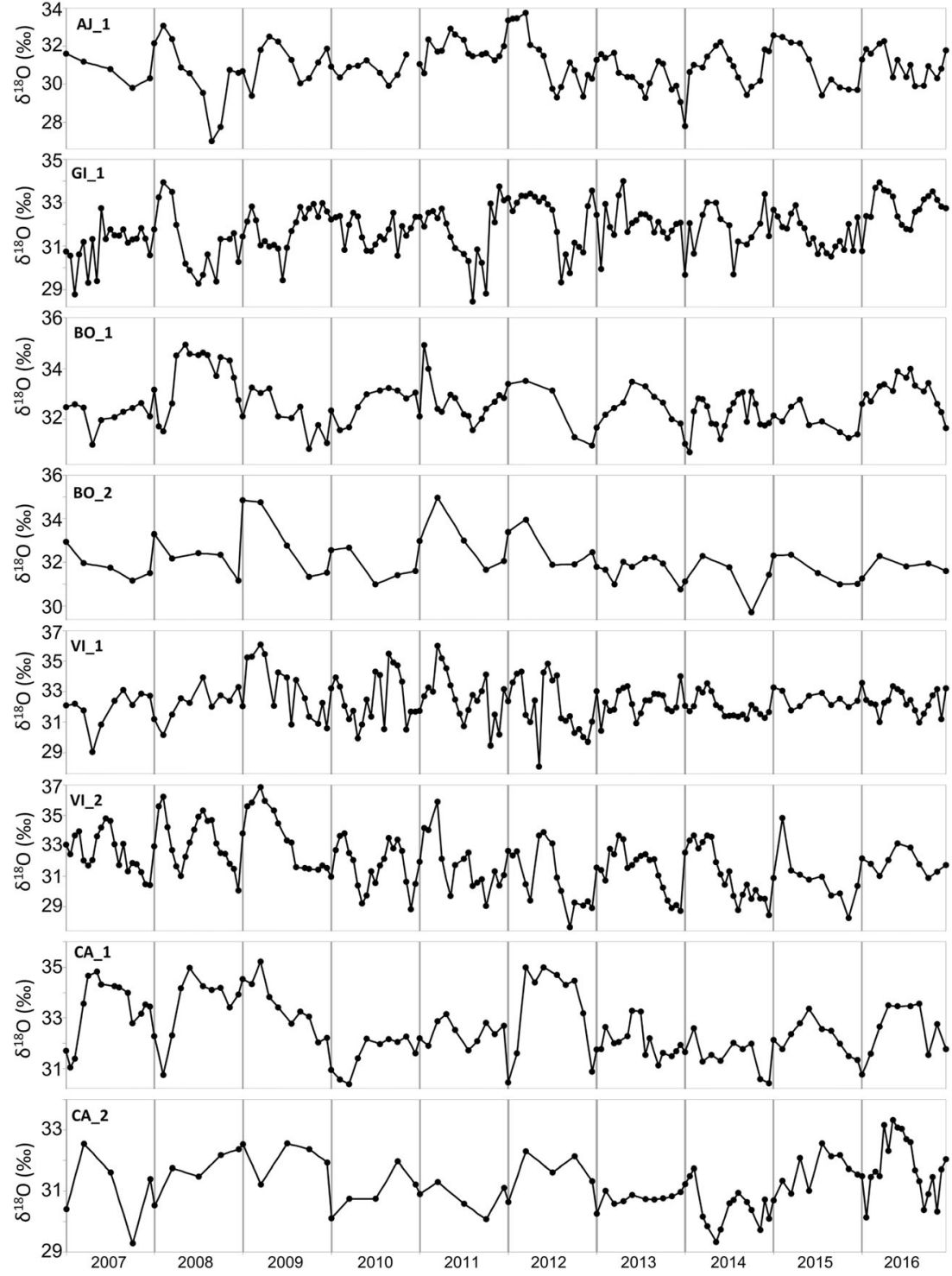

characterized by a minimum $\delta^{18} \mathrm{O}_{\mathrm{TRC}}$ in the first part of the tree ring and a maximum in the second part. Isotope pattern 1

Table 2 Pearson's correlation coefficients between the intra-annual oxygen isotope chronologies of each tree over the time period 20072016. The tree ID is explained in Table 1. Significant correlations $(p<$ 0.05 ) are indicated in italic

\begin{tabular}{lccccccc}
\hline & BO_1 & BO_2 & CA_1 & CA_2 & GI_1 & VI_1 & VI_2 \\
\hline AJ_1 & -0.05 & 0.44 & -0.19 & -0.10 & 0.31 & -0.02 & 0.12 \\
BO_1 & & 0.25 & 0.34 & 0.13 & 0.00 & 0.28 & 0.30 \\
BO_2 & & & 0.26 & 0.12 & 0.12 & 0.33 & 0.54 \\
CA_1 & & & & 0.52 & -0.21 & 0.12 & 0.26 \\
CA_2 & & & & & -0.05 & 0.03 & 0.13 \\
GI_1 & & & & & & -0.03 & 0.05 \\
VI_1 & & & & & & & 0.36 \\
\hline
\end{tabular}

occurred at each site except Ajaccio. Isotope pattern 2 (16 times) did not occur at coastal locations and was characterized by low $\delta^{18} \mathrm{O}_{\mathrm{TRC}}$ values in the beginning of the tree ring, a steep increase to a maximum at position 12 , followed by a relatively stable phase with high $\delta^{18} \mathrm{O}_{\mathrm{TRC}}$ values and a declining trend towards the end of the tree ring. Isotope pattern 3 ( 25 times) was characterized by high $\delta^{18} \mathrm{O}_{\mathrm{TRC}}$ values in the beginning and low $\delta^{18} \mathrm{O}_{\text {TRC }}$ values at the end of the tree ring, with a more or less continuously decreasing trend over the whole tree ring. This pattern was found at all sites.

\subsection{Major features of the intra-annual oxygen isotope chronology over 30 years}

The 30-year long intra-annual oxygen isotope chronology from site Capannelle also showed a very high intra-annual variability, with more diverse isotope patterns in the earlier 
than in the later years (Fig. 3). The extremely narrow tree ring 2001 could only be separated into three slices. With this low sample depth, it was not possible to describe an isotope pattern, so we excluded this year from further analysis. Similar to the 10-year chronologies, the isotope patterns from tree CA_1 for the time period 1987-2016 were separated by the cluster analysis into four groups, corresponding to isotope pattern 1 (6 years), isotope pattern 2 (7 years), isotope pattern 3 ( 8 years), and isotope pattern 4 ( 8 years). The mean isotope patterns for each group were similar to the mean isotope patterns derived from the 100 tree rings of eight trees from all sites, confirmed by high correlation values ranging between 0.85 and 0.99 between the respective patterns. While isotope pattern 1 mainly occurred in the earlier years and not after 2004, isotope pattern 2 was more common in more recent years, especially from 2007 onwards.

Climate characteristics of the years of the four isotope patterns were derived from the analysis of tree CA_1 (Fig. 4c). Years with isotope pattern 1 were characterized by a warm-dry DJF, followed by a cold-dry MAM. JJA and SON were both warm-wet. Years with isotope pattern 2 were characterized by high temperatures during all seasons except SON and high precipitation amounts except in JJA. The highest JJA temperatures and lowest JJA precipitation amounts were reported for these years. The lowest DJF temperatures and highest DJF precipitation amounts occurred in years with isotope pattern 3. All seasons except SON were cold with varying precipitation amounts. Years with isotope pattern 4 were characterized by moderate climate conditions. All seasons except MAM were rather cold-dry, but showed only small deviations from the long-term mean.

\subsection{Climate-isotope relationship}

Correlation coefficients between the mean isotope patterns and climate parameters (Fig. 5) were given in Table 3. On the tree level, the mean isotope pattern of tree CA_1 showed the strongest correlations with climate parameters during the growth season. Tree CA_2 showed weaker correlations, but of the same signs. The same correlation pattern could be observed for tree BO_1. A completely opposite correlation pattern could be found for trees AJ_1 and GI_1. Trees BO_1 and VI_1 showed only one significant correlation, while tree VI__1 was not significantly correlated with any climate parameter. The four different isotope patterns from tree CA_1 showed different dependencies to the climate variables over the growth season. While isotope patterns 2 and 4 were significantly correlated with all tested climate parameters, isotope pattern 1 showed no significant correlation at all, and isotope pattern 3 only with air humidity.

\section{Discussion}

\subsection{Methodological constraints}

The separation of high-resolution samples from tree rings is traditionally conducted by microtomes (e.g., Evans and Schrag 2004; Helle and Schleser 2004; Poussart et al. 2004) or by the manual separation with a razor blade (e.g., Schubert and Jahren 2015). No consensus exists whether the tree rings should be separated into pieces of similar width (e.g., Berkelhammer and Stott 2009; Zhu et al. 2012) or into similar numbers of samples per ring (e.g., Poussart et al. 2004; Roden et al. 2009). In our study, the number of samples per ring varied with treering width and was restricted by the necessity of obtaining enough material for cellulose extraction for stable isotope analyses. Concerning this criterion, it becomes obvious that due to the higher density of the latewood, the latewood portion of the ring is overrepresented in years with broad early wood and narrow dense latewood. It is questionable if a better comparison with climate parameters is possible when using pieces of similar width. The formation of the tree ring is not linear over the growth season, i.e., not each part of the tree ring represents a similar time period. The largest part of the tree ring is formed during the early phase of the growth season (e.g., Ziaco and Biondi 2016). Additional uncertainties are the exact

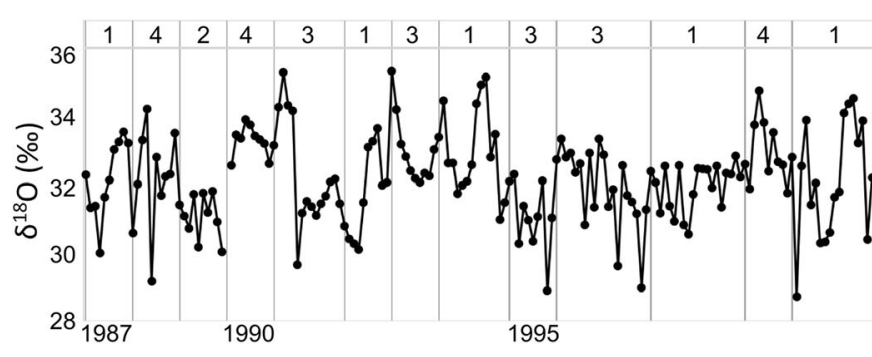

Fig. 3 Thirty years of intra-annual oxygen isotope variations of one tree at site Capannelle. The number of values per year varies between 3 and 20 , depending on the tree-ring width in the respective year. The numbers

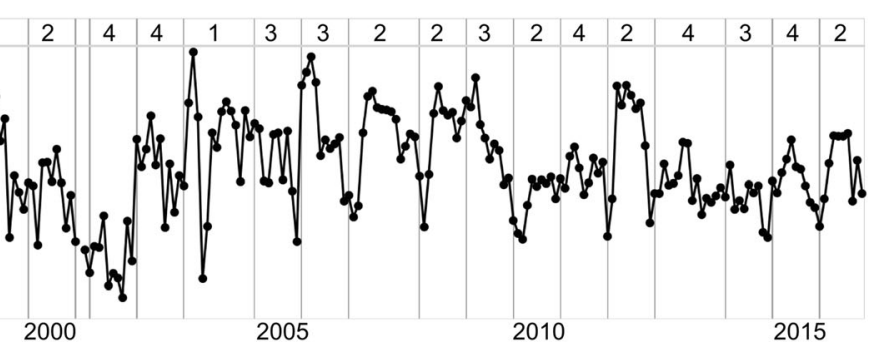

in the upper panel are the numbers of the intra-annual isotope pattern to which this year belongs 
(a) 2007-2016 from eight trees

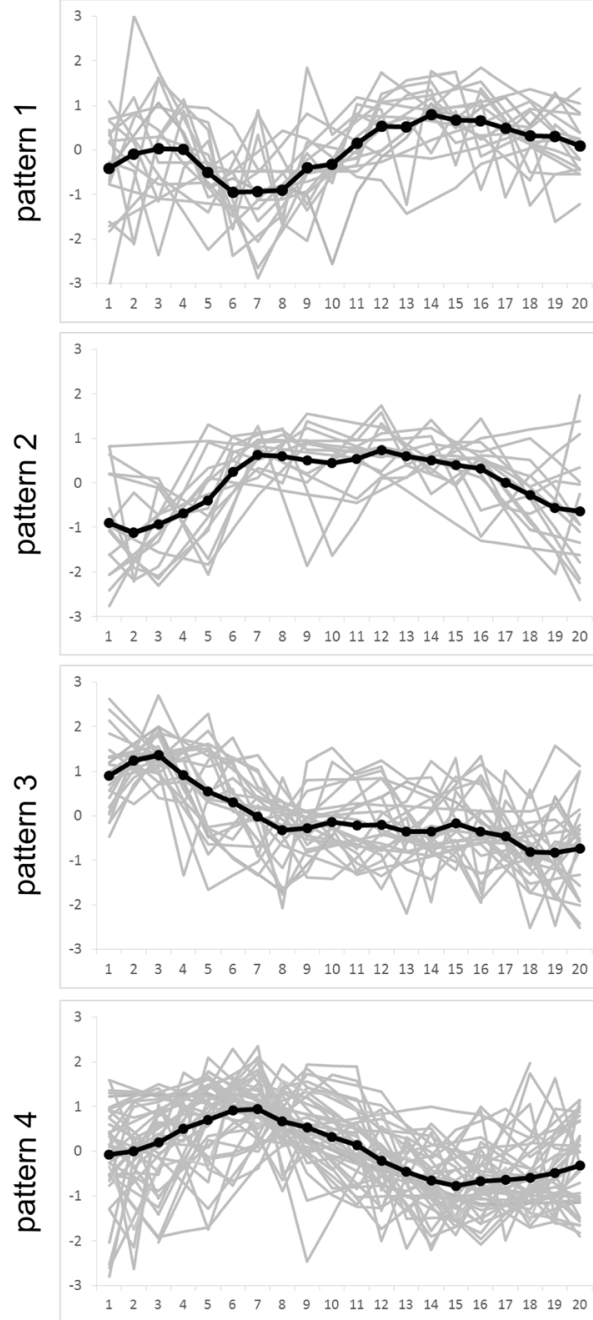

(b) $1987-2016$ from one tree

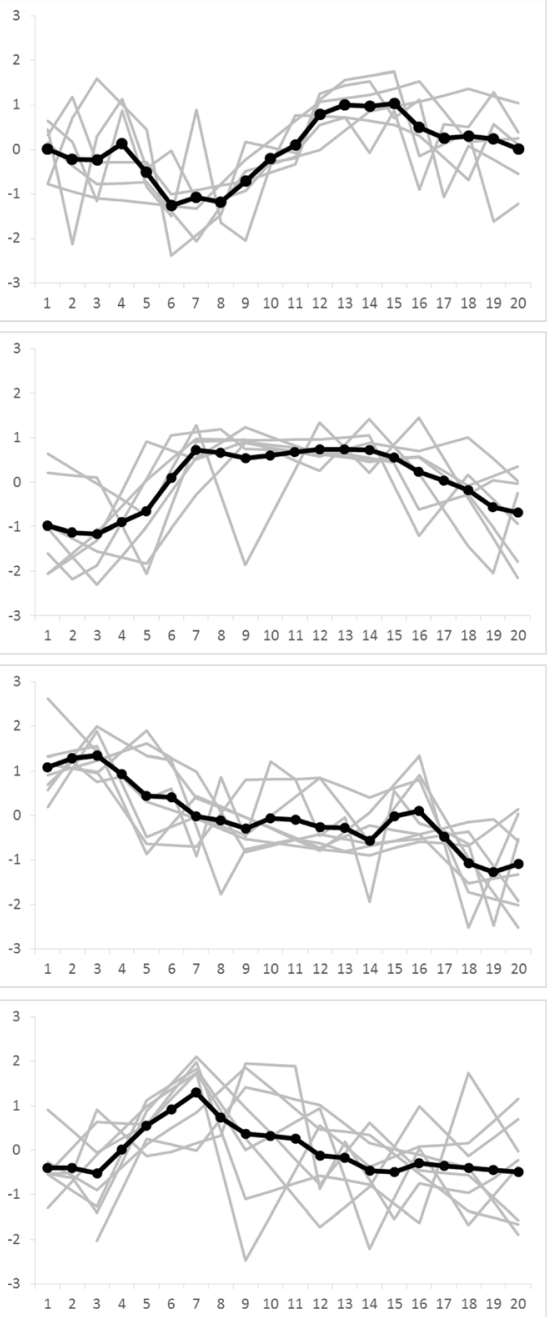

(c) climate characteristics

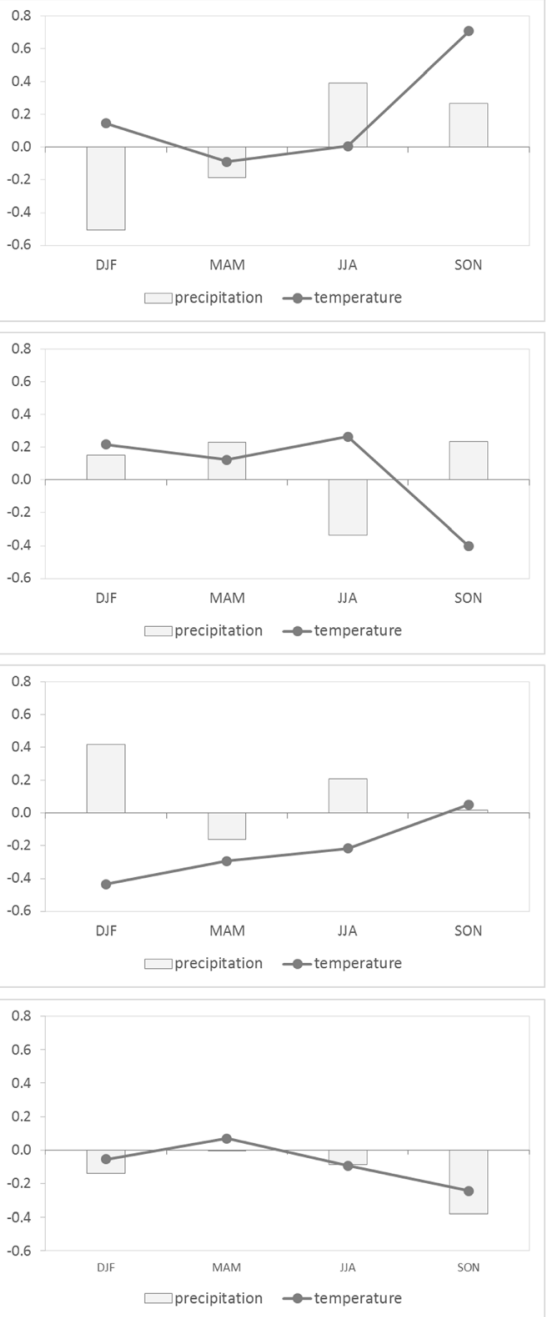

Fig. 4 Four different intra-annual oxygen isotope patterns derived from 100 tree rings of eight trees from five different sites over the time period 2007-2016 (a) and from one tree from one site (tree CA_1) over the time period 1987-2016 (b). The black lines represent the mean intra-annual oxygen isotope pattern. The mean climate characteristics, presented as

timing of the duration of the growth season, which varies with elevation, and ambiguity how specific environmental factors influence cellular division, growth, and maturation (Moser et al. 2010). By comparing isotope patterns from sites with different ecological and climatological conditions, it is even more difficult to assign portions of tree rings to similar times and climate conditions, since growth is restricted by different factors and a similar change of one climate parameter can influence growth in opposing ways. These uncertainties should be kept in mind for the interpretation of the isotope patterns and the establishment of a climate-isotope relationship in the following paragraphs. Future studies using dendrometer data and wood anatomical analyses of cambial activity from the same trees as used for the isotope analysis will allow us to exactly date the different parts of the tree rings. deviations from the long-term mean, are given in c. Climate data were derived from the Météo France climate station Evisa for the years when the corresponding pattern occurs in tree CA_1. For better comparison, all parameters were z-transformed.

\subsection{Interpretation of the intra-annual isotope patterns derived from the tree at Capannelle}

The observation of the four isotope patterns in the 30-year long chronology from Capannelle allows a direct comparison of the isotope patterns with climate characteristics in the years of their occurrence. Based on correlations with climate parameters during the growth season (Table 3, Fig. 4), it is possible to distinguish between isotope patterns reporting strong correlations with climate characteristics of the growth season (patterns 2 and 4) and isotope patterns which are influenced by other factors (patterns 1 and 3). In years with isotope patterns 2 and 4, both the autumn-winter prior to the growth season and the growth season are dry, whereas they are wet in years with isotope patterns 1 and 3, respectively. In case of dry autumn-winter conditions, it can be assumed that soil 

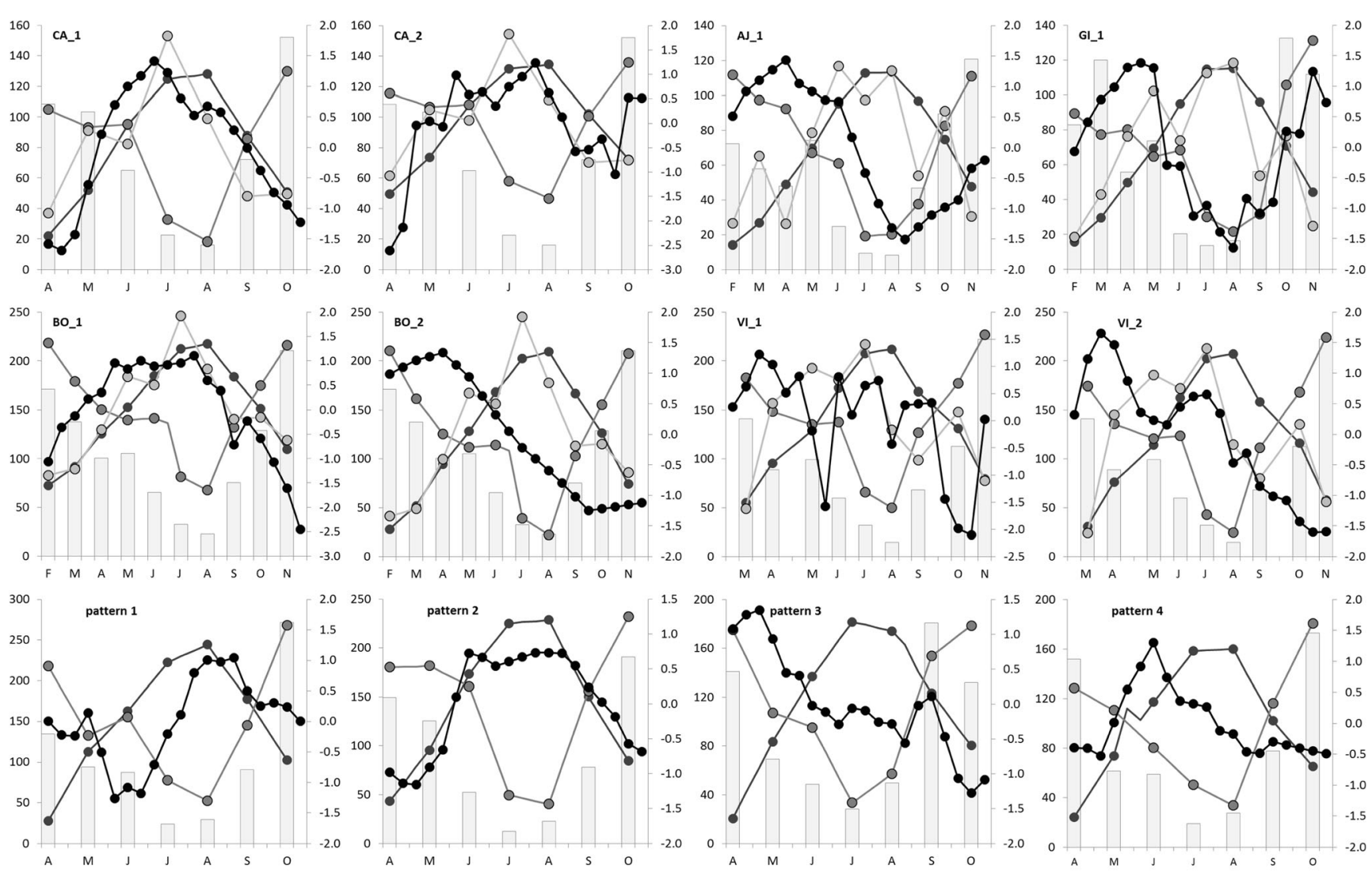

$\square$ precipitation -temperature -air humidity od180 precipitation $\bullet-\mathrm{d} 180$ cellulose

Fig. 5 Mean intra-annual $\delta^{18} \mathrm{O}$ patterns for each analyzed tree over the period 2007-2016 (rows 1 and 2) and for the four patterns derived from tree CA_1 over the period 1987-2016 (row 3). The explanation of site abbreviations is the same as in Fig. 2. The intra-annual $\delta^{18} \mathrm{O}$ pattern of tree-ring cellulose is compared with seasonal fluctuations of the climate parameters mean temperature, air humidity, precipitation, and $\delta^{18} \mathrm{O}$ values of precipitation during the growing season. The monthly means for climate parameters and $\delta^{18} \mathrm{O}$ values of precipitation were calculated for the time periods 2007-2016 and 2014-2016, respectively (rows 1 and 2 ), and for years when the corresponding pattern occurs (row 3). Due to the low number of available years, patterns in row 3 are not compared with $\delta^{18} \mathrm{O}$ values of precipitation. For better comparison, all parameters (except precipitation) were z-transformed water reservoirs are not refilled adequately and trees depend more on precipitation during the growth season as main water source. In case of wet conditions, more soil water is available for the trees and hence, isotope patterns possibly report a mixed climate-soil water signal which results in weak correlations with climate parameters. Isotope patterns 2 and 4 are more common in recent years compared with those in the earlier years of the 30-year study period, which confirms a trend towards more pronounced drought stress in summer. Such a drying trend is also observable in the instrumental climate data.

A closer look on the isotope patterns reveals that patterns with similar characteristics of precipitation during vegetation dormancy and growth season are in good concordance with the early part of the tree ring from positions 1 to 7 (Fig. 4). Wet conditions entrain a decline of isotope values in the beginning, dry conditions, and increase. In the Mediterranean area, water in deeper soil horizons is less enriched in ${ }^{18} \mathrm{O}$ than close to the soil surface because it represents mainly winter precipitation, i.e., precipitation with lower isotopic values than summer precipitation, and is less exposed to evaporation (Sarris et al. 2013). The tapping of these deeper water sources available to deeprooted trees during the growth season can explain the observed declining trend of $\delta^{18} \mathrm{O}_{\mathrm{TRC}}$. In case of dry conditions, the deeper soil water reservoirs are already exploited in the early phase of the growth season. The observed increase in $\delta^{18} \mathrm{O}_{\mathrm{TRC}}$ may indicate the transition from the use of deeper soil water to current precipitation.

\subsection{Distribution of intra-annual isotope patterns among trees and sites}

The high variability of isotope patterns (each tree shows at least two different patterns within the 10 studied years) underlines the complexity of the transformation of oxygen isotope ratios from their source into cellulose in pine trees on Corsica. Even within one site, trees can show different isotope patterns 
Table 3 Pearson's correlation coefficients between mean intra-annual $\delta^{18} \mathrm{O}$ patterns of eight studied trees (explanation of tree ID in Table 1) or four averaged seasonal stable isotope patterns from tree CA_1 and climate parameters. Significant values $(p<0.05)$ are indicated in italic. Instrumental meteorological data from the closest climate stations were used as climate variables. The relationships were calculated between the mean intra-annual $\delta^{18} \mathrm{O}$ patterns and the mean climate parameters during the growing season over the time period 2007-2016. The $\delta^{18} \mathrm{O}$ values of precipitation are from four stations close to the studied transect and only cover the time period 2014-2016

\begin{tabular}{lcccc}
\hline & Air humidity & Temperature & Precipitation & \multicolumn{1}{c}{$\delta^{18} \mathrm{O}$ precipitation } \\
\hline AJ_1 & 0.54 & -0.60 & 0.10 & -0.31 \\
BO_1 & -0.77 & 0.62 & -0.81 & 0.73 \\
BO_2 & 0.14 & -0.46 & 0.06 & -0.26 \\
CA_1 & -0.71 & 0.94 & -0.83 & 0.77 \\
CA_2 & -0.37 & 0.70 & -0.36 & 0.63 \\
GI_1 & 0.76 & -0.71 & 0.63 & -0.37 \\
VI_1 & -0.12 & -0.08 & -0.11 & 0.02 \\
VI_2 & -0.25 & -0.12 & -0.32 & 0.25 \\
Pattern 1 & 0.13 & 0.10 & -0.10 & -0.13 \\
Pattern 2 & -0.74 & 0.90 & -0.74 & 0.55 \\
Pattern 3 & -0.36 & -0.15 & -0.06 & -0.05 \\
Pattern 4 & -0.56 & 0.37 & -0.38 & 0.43 \\
\hline
\end{tabular}

in the same year. Additionally, the isotope patterns are not evenly distributed between the sites with isotope pattern 2 only occurring at mid- and high-elevation sites.

The mean isotope pattern of each tree can be attributed to one of the four isotope patterns identified by cluster analysis. Trees BO_1, CA_1, and CA_2 correspond to pattern 2; VI_1 and VI_2 to pattern 3; and AJ_1, BO_2, and GI_1 to pattern 4. The most obvious difference is observable for the coastal trees with higher $\delta^{18} \mathrm{O}_{\mathrm{TRC}}$ values in the beginning and a more pronounced decrease in the second half of the tree ring. This isotope pattern (pattern 4) occurring at coastal sites is similar to the pattern observed by Roden et al. (2009) for coastal redwood (Sequoia sempervirens) in California. The authors related high $\delta^{18} \mathrm{O}_{\mathrm{TRC}}$ values at the ring boundary to organic matter formed at the end of the previous growth season and utilized for xylem formation at the beginning of the new growth season. The following decline in $\delta^{18} \mathrm{O}$ is interpreted as a combined effect of the reduction in the reservoir pool of previous years' carbohydrates and an increase in the inputs of current photosynthates with isotopic spring signature (Roden et al. 2009). At our sites, vegetation dormancy at coastal locations is considerably shorter than at high-elevation sites, making it more likely that stored reserves are used. Soils at coastal locations are deeper and characterized by a better waterholding capacity than the shallow soils at high-elevation sites. The groundwater reservoir available for the trees is larger, and the isotopic signature of winter precipitation is imprinted considerably in tree-ring cellulose by low values.
Existing studies developed intra-annual oxygen isotope chronologies from a wide range of different tree species and climate conditions. Similar isotope patterns as in our study have been reported by other authors. In Pinus halepensis growing in the eastern Mediterranean, Sarris et al. (2013) observed an isotope pattern similar to our pattern 2 in a dry year and a similar pattern to our pattern 4 in a wet year. A similar pattern to our pattern 2 was described by Treydte et al. (2014) for Larix decidua in Switzerland. Berkelhammer and Stott (2009) described two isotope patterns for Pinus longaeva in California which are similar to our patterns 2 and 3 . While some authors found a strong coherency of isotope patterns among different years and sites (e.g., Roden et al. 2009), other studies observed high variabilities as in our study (e.g., Schubert and Jahren 2015). Although our sites are located close by compared with other studies (for example 250-km distance between sites in Roden et al. (2009)), the isotope patterns seem to change over time and within single trees. High correspondence between distant sites indicates that a large-scale environmental forcing determines the isotopic signature (i.e., global circulation patterns like ENSO or the monsoon system). High diversity, in contrast, underlines the importance of local site conditions and individual tree physiological status, which overlap with the influence of the large-scale environmental forcing. Our sites, although rather close to each other, are affected by a very strong gradient in ecological conditions, ranging from typical Mediterranean to subalpine environments, which lead to a complex and highly variable isotope transfer from source to sink.

\subsection{Climate signals of the intra-annual isotope patterns}

According to Treydte et al. (2014), strongest climate signals in $\delta^{18} \mathrm{O}_{\text {TRC }}$ chronologies should be recorded at sites where soils are mainly supplied with precipitation water during the growth season. This is not the case for the Mediterranean region, where winter precipitation is the main source for soil water reservoirs. On the other hand, Berkelhammer and Stott (2009) showed that in areas where cellulose synthesis and the occurrence of precipitation are decoupled and occur in different seasons of the year, distinct information on both seasons can be captured in the intra-annual cycle. The results of our study from a Mediterranean location indicate that two out of four isotope patterns are mainly influenced by the climate conditions during the growth season.

On the tree level, we observed different climate sensitivities. Strong positive correlations with temperature and $\delta^{18} \mathrm{O}$ of precipitation and negative correlations with air humidity and precipitation are reported for three trees. The trees BO_1, CA_1, and CA_2 have no or only 
limited access to groundwater and therefore depend on precipitation during the growth season as water source. The $\delta^{18} \mathrm{O}$ values of summer precipitation are reflected in $\delta^{18} \mathrm{O}_{\mathrm{TRC}}$, as indicated by strong correlations. In contrast, the studied trees at coastal sites (AJ_1 and GI_1) show an opposite correlation pattern. These trees have access to groundwater, which can partly explain the observed correlations. In case of high temperatures and low air humidity, $\delta^{18} \mathrm{O}_{\mathrm{TRC}}$ is low in these trees, since water loss at the leaf level can be compensated by water extracted from the ground. In case of low temperature, high precipitation amount, and high air humidity, summer precipitation water can be used by the trees, as reflected by higher $\delta^{18} \mathrm{O}_{\mathrm{TRC}}$. The weak correlations with climate parameters of trees BO_2, VI_1, and VI_2 indicate that the isotope patterns of these trees depend more on other factors than climate conditions during the growth season. With our approach, we cannot distinguish whether these weak correlations result from varying water sources or changes in the rate of transpiration during the growth season.

A direct comparison between isotope patterns and seasonal fluctuations of climate parameters can be hampered in several ways. First, trees can use stored carbohydrates for xylem formation at the beginning of the growth season. These carbohydrates can have a different isotopic signature, depending on the temperature and $\delta^{18} \mathrm{O}$ value of precipitation during the time of formation (Dodd et al. 2008). If temperature and $\delta^{18} \mathrm{O}$ values of precipitation are similar at the end and at the beginning of the growth season, the stored carbohydrates have the same isotopic signature as carbohydrates formed in the early growing season. However, even if the $\delta^{18} \mathrm{O}$ values of stored carbohydrates and cellulose produced under early growth season conditions are different, this difference can be eliminated through the exchange of 30 to $40 \%$ of oxygen atoms during the cell formation process (Roden et al. 2000). Second, fluctuations in the contribution of snowmelt to groundwater in the early growth season can distort the climate-isotope relationship, because the isotopic signature of snowmelt is lower than that of liquid precipitation (Dodd et al. 2008). Third, the dependency of $\delta^{18} \mathrm{O}_{\mathrm{TRC}}$ on the isotopic composition of the source water can distort the climateisotope relationship. Depending on rooting depth, trees have access to different water pools with varying isotopic signatures. Deeper water pools become most important when the topsoil moisture pools dry out. Water reserves in deeper soil layers can even represent a long-term mean isotopic value of winter precipitation and hence do not only reflect the amount of winter precipitation prior to the growth season. Fourth, the rate of transpiration can change over the growth season, distorting a linear relationship between a climate parameter and the isotope pattern.

\section{Conclusion}

The presented intra-annual isotope patterns from eight trees from five different locations show a high variability of different patterns among trees, sites, and years. Isotope patterns from trees growing on shallow and less developed soils in the higher mountain areas mainly depend on the climatic conditions during the growth season and therefore can be used to reconstruct past climate conditions in high temporal resolution. The analyses of the 30 -year long intra-annual oxygen isotope chronology reveal that the stable isotope pattern reflecting dry-warm conditions during summer occurs with a higher frequency after 2007, thus confirming a trend towards pronounced drought stress during summer. This might become critical for Pinus nigra trees growing at dry sites if becoming more extreme in the future. In contrast, trees at coastal locations have access to groundwater and depend more on the refilling of the water reservoir during winter time. Until now, the isotope patterns are not yet precisely dated to the exact time of their formation within the vegetation period. Complementary studies using dendrometer data and wood anatomical analyses of cambial activity will help to determine the exact timing of the growth season length and to assign precise formation dates of different parts of the tree rings. Measurements of $\delta^{18} \mathrm{O}$ values in needle water, branch water, soil water, and precipitation in high temporal resolution will allow tracing back the isotopic source signal and to identify the major isotope fractionation processes in a broad range of different ecological conditions.

Acknowledgments We thank Iris Burchardt and Roswitha Höfner-Stich for their support during cellulose extraction and isotope analyses.

Funding This work was funded by the German Research Foundation (DFG, project bundle PAK 927/1) as part of the CorsicArchive subprojects "Climatic impact on functional wood anatomy, seasonal wood formation, and tree growth along altitudinal gradients on Corsica" and "Spatial and temporal variability of stable oxygen isotopes in wood of pine trees on Corsica as indicators of current and past hydroclimate" (BR 1895/27-1; SZ 356/1-1).

Statement on data availability The datasets generated and/or analyzed during the current study are available from the corresponding author on reasonable request.

\section{Compliance with ethical standards}

Conflict of interest The authors declare that they have no conflict of interest. 


\section{Appendix}

complete linkage

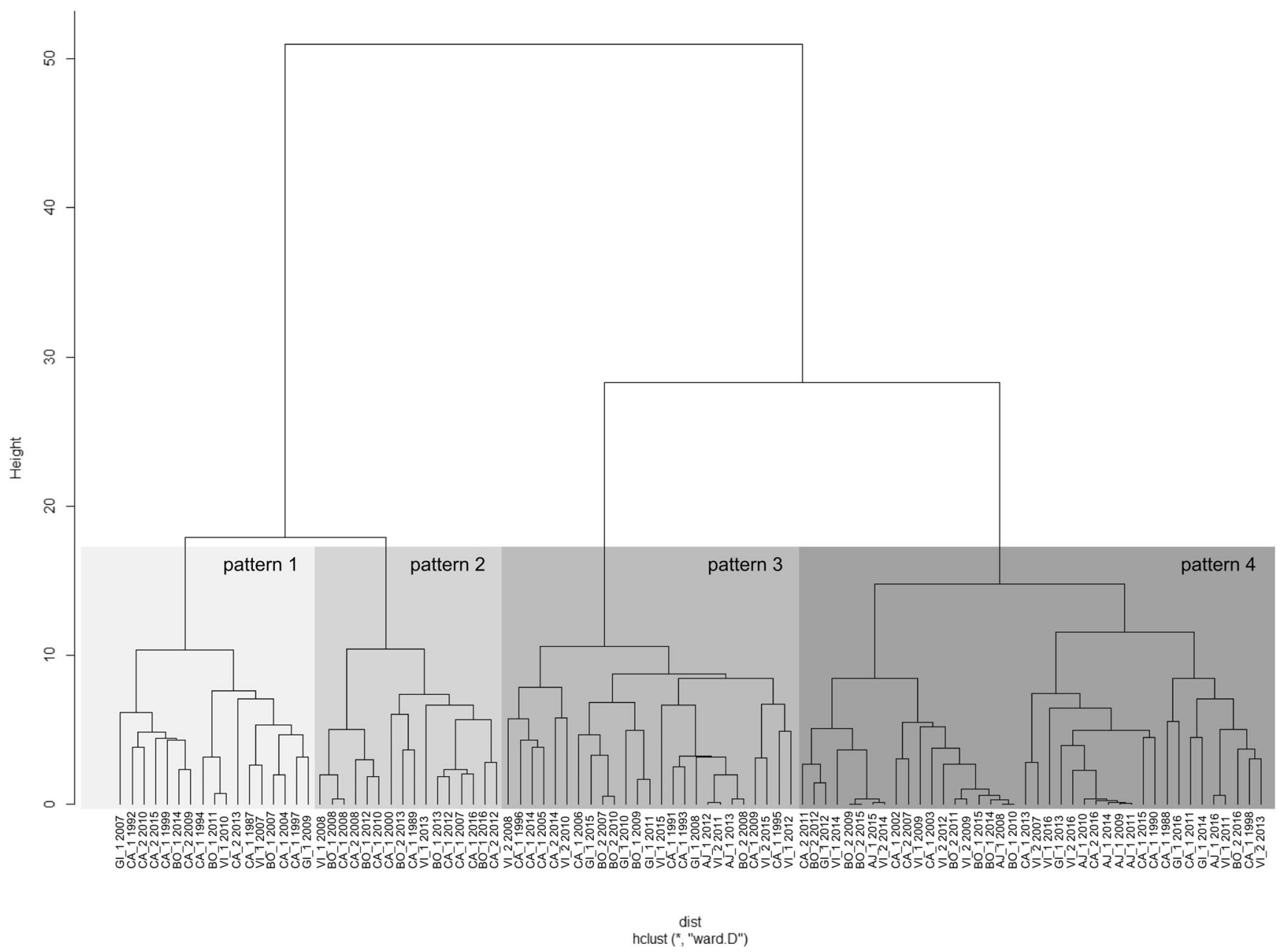

Fig. 6 Result of the cluster analysis for the detection of different intra-annual oxygen isotope patterns in the tree-rings. Each gray-shaded box represents one of the patterns

\section{References}

Barbour M, Walcroft A, Farquhar G (2002) Seasonal variation in $\delta^{13} \mathrm{C}$ and $\delta^{18} \mathrm{O}$ of cellulose from growth rings of Pinus radiata. Plant Cell Environ 25:1483-1499

Berkelhammer M, Stott LD (2009) Modeled and observed intra-ring $\delta^{18} \mathrm{O}$ cycles within late Holocene Bristlecone Pine tree samples. Chem Geol 264:12-23

Brienen RJW, Helle G, Pons TL, Guyot J-L, Gloora M (2012) Oxygen isotopes in tree rings are a good proxy for Amazon precipitation and El Nino-Southern Oscillation variability. Proc Natl Acad Sci U S A 42:16957-16962

Bruno C, Dupre G, Giorgetti G, Borne D (2001) Chì tempu face? Météorologie, climat et microclimats de la Corse. CNDP-CRDP de Corse/MétéoFrance, Ajaccio, France

Danis PA, Masson-Delmotte V, Stievenard M, Guillemin MT, Daux V, Naveau P, von Grafenstein U (2006) Reconstruction of past precipitation $\delta^{18} \mathrm{O}$ using tree-ring cellulose $\delta^{18} \mathrm{O}$ and $\delta^{13} \mathrm{C}$ : a calibration study near Lac d'Annecy, France. Earth Planet Sci Lett 243:439448
Dodd JP, Patterson WP, Holmden C, Brasseur JM (2008) Robotic micromilling of tree-rings: a new tool for obtaining subseasonal environmental isotope records. Chem Geol 252:21-30

Edwards TWD, Birks SJ, Luckman BH, MacDonald GM (2008) Climatic and hydrologic variability during the past millennium in the eastern Rocky Mountains and northern Great Plains of western Canada. Quat Res 70:188-197

Evans MN, Schrag DP (2004) A stable isotope - based approach to tropical dendroclimatology. Geochim Cosmochim Acta 68:3295-3305

Formayer H, Haas P, Hofstätter M, Radanovics S, Kromp-Kolb H (2007) Räumlich und zeitlich hochaufgelöste Temperaturszenarien für Wien und ausgewählte Analysen bezüglich Adaptionsstrategien. BOKU-Met Bericht

Gessler A, Brandes E, Buchmann N, Helle G, Rennenberg H, Barnard R (2009) Tracing carbon and oxygen isotope signals from newly assimilated sugars in the leaves to the tree-ring archive. Plant Cell Environ 32:780-795

Grießinger J, Bräuning A, Helle G, Thomas A, Schleser GH (2011) Late Holocene Asian summer monsoon variability reflected by $\delta^{18} \mathrm{O}$ in tree-rings from Tibetan junipers. Geophys Res Lett. https://doi.org/ 10.1029/2010GL045988 
Guijarro JA (2018) Climatol: climate tools (series homogenization and derived products). R-project. https://cran.r-project.org/package $=$ climatol (17.01.2019)

Häusser M, Szymczak S, Garel E, Huneau F, Santoni S, Bräuning A (2019a) Impact of two consecutive extreme years on radial growth of pines along an elevation gradient on Corsica. In: Battipaglia G, Marzaioli R (eds) Proceedings of the tree-rings in archaeology, climatology and ecology TRACE 2019. p. 48

Häusser M, Szymczak S, Garel E, Santoni S, Huneau F, Bräuning A (2019b) Growth variability of two native pine species on Corsica as a function of altitude. Dendrochronolgia 54:49-55

Helle G, Schleser GH (2004) Interpreting climate proxies from tree-rings. In: Fischer H, Floeser G, Kumke T, Lohmann G, Miller H, JFW N, von Storch $\mathrm{H}$ (eds) The KIHZ project: towards a synthesis of Holocene proxy data and climate models. Springer, Verlag, pp $129-148$

Jahren AH, Sternberg LSL (2003) Humidity estimate for the middle Eocene Arctic rain forest. Geology 31:463-466

Klein T, Hemming D, Lin T, Grünzweig JM, Maseyk K, Rotenberg E, Yakir D (2005) Association between tree-ring and needle $\delta^{13} \mathrm{C}$ and leaf gas exchange in Pinus halepensis under semi-arid conditions. Oecologia 144:45-54

Li ZH, Labbé N, Driese SG, Grissino-Mayer HD (2011) Micro-scale analysis of tree-ring $\delta^{18} \mathrm{O}$ and $\delta^{13} \mathrm{C}$ on $\alpha$-cellulose spline reveals high-resolution intraannual climate variability and tropical cyclone activity. Chem Geol 284:138-147

Liu X, An W, Treydte K, Shao X, Leavitt S, Hou S, Chen T, Sun W, Qin $\mathrm{D}$ (2012) Tree-ring $\delta^{18} \mathrm{O}$ in southwestern China linked to variations in regional cloud cover and tropical sea surface temperature. Chem Geol 291:104-115

McCarroll D, Loader NJ (2004) Stable isotopes in tree rings. Quat Sci Rev 23:771-801

Météo France (2018) Climate Data from stations Ajaccio, Bocognano, Evisa, Sampolo and Solenzara. https://www.meteofrance.fr/ (16.03. 2018)

Miller DL, Mora CI, Grissino-Mayer HD, Mock CJ, Uhle ME, Sharp Z (2006) Tree-ring isotope records of tropical cyclone activity. Proc Natl Acad Sci U S A 103:14294-14297

Moser L, Fonti P, Büntgen U, Esper J, Luterbacher J, Franzen J, Frank D (2010) Timing and duration of European larch growing season along altitudinal gradients in the Swiss Alps. Tree Physiol 30:225-233

Offermann C, Ferrio JP, Holst J, Grote R, Siegwolf R, Kayler Z, Gessler A (2011) The long way down - are carbon and oxygen isotope signals in the tree ring uncoupled from canopy physiological processes? Tree Physiol 31:1088-1102

Oksanen J (2018) Vegan: community ecology package. R-project. https:// cran.r-project.org/web/packages/vegan/index.html (17.01.2019)

Poussart PF, Evans MN, Schrag DP (2004) Resolving seasonality in tropical trees: multi-decade, high-resolution oxygen and carbon isotope records from Indonesia and Thailand. Earth Planet Sci Lett 218: 301-316

Poussart PM, Myneni SCB, Lanzirotti A (2006) Tropical dendrochemistry: a novel approach to estimate age and growth from ringless trees. Geophys Res Lett. https://doi.org/10.1029/ 2006GL02629

R Core Team (2009) The R stats package. R-project. http://stat.ethz.ch/Rmanual/R-devel/library/stats/html/stats-package.html (17.01.2019)

R Core Team (2019) R: a language and environment for statistical computing. R Foundation for Statistical Computing, Vienna, Austria. https://www.r-project.org (17.01.2019)

Reynolds-Henne CE, Siegwolf RTW, Treydte K, Esper J, Henne S, Saurer M (2007) Temporal stability of climate-isotope relationships in tree rings of oak and pine (Ticino, Switzerland). Glob Biogeochem Cycles 21:GB4009

Richter SL, Hohnson AH, Dranoff MM, Taylor KD (2008) Continentalscale patterns in modern wood cellulose $\delta^{18} \mathrm{O}$ : implications for interpreting paleowood cellulose $\delta^{18} \mathrm{O}$. Geochim Cosmochim Acta $72: 2735-2743$

Robertson I, Waterhouse JS, Barker AC, Carter AHC, Swistur VR (2001) Oxygen isotope ratios of oak in east England: implications for reconstructing the isotopic composition of precipitation. Earth Planet Sci Lett 191:21-31

Roden JS, Lin G, Ehleringer JR (2000) A mechanistic model for interpretation of hydrogen and oxygen isotope ratios in tree-ring cellulose. Geochim Cosmochim Acta 64:21-35

Roden JS, Johnstone JA, Dawson TE (2009) Intra-annual variation in the stable oxygen and carbon isotope ratios of cellulose in tree rings of coast redwood (Sequoia sempervirens). Holocene 19:189-197

Sarris D, Siegwolf R, Körner C (2013) Inter- and intra-annual stable carbon and oxygen isotope signals in response to drought in Mediterranean pines. Agric For Meteorol 168:59-68

Saurer M, Kress A, Leuenberger M, Rinne KT, Treydte KS, Siegwolf RTW (2012) Influence of atmospheric circulation patterns on the oxygen isotope ratio of tree rings in the Alpine region. J Geophys Res 117:D05118

Schubert BA, Jahren AH (2015) Seasonal temperature and precipitation recorded in the intra-annual oxygen isotope pattern of meteoric water and tree-ring cellulose. Quat Sci Rev 125:1-14

Szejner P, Wright WE, Belmecheri S, Meko D, Leavitt SW, Ehleringer JR, Monson RK (2018) Disentangling seasonal and interannual legacies from inferred patterns of forest water and carbon cycling using tree-ring stable isotopes. Glob Chang Biol 24:5332-5347

Szymczak S, Joachimski MM, Bräuning A, Kuhlemann J (2011) Comparison of carbon and oxygen isotope chronologies from different wood components of Pinus nigra ssp. laricio (Corsica/ France). Dendrochronologia 29:219-226

Treydte K, Frank D, Esper J, Andreu L, Bednarz Z, Berninger F, Boettger T, D'Alessandro CM, Etien N, Filot M, Grabner M, Guillemin MT, Guiterrez E, Haupt M, Helle G, Hilasvuori E, Jungner H, KalelaBrundin M, Krapiec M, Leuenberger M, Loader NJ, MassonDelmotte V, Pazdur A, Pawelczyk S, Pierre M, Planells O, Pukine R, Reynolds-Henne CE, Rinne KT, Saracino A, Saurer M, Sonninen E, Stievenard M, Swistur VR, Szczepanek M, Szychowska-Krapiec E, Todaro L, Waterhouse JS, Weigl M, Schleser GH (2007) Signal strength and climate calibration of a European tree-ring isotope network. Geophys Res Lett 34:L24302

Treydte K, Boda S, Pannatier EG, Fonti P, Frank D, Ullrich B, Saurer M, Siegwolf R, Battipaglia G, Werner W, Gessler A (2014) Seasonal transfer of oxygen isotopes from precipitation and soil to the tree ring: source water versus needle water enrichment. New Phytol 202: $772-783$

United States Geological Survey (2018) Shuttle radar topography mission. https://ta.cr.usgs.gov/SRTM/ (15.01.2018)

Verheyden A, Helle G, Schleser GH, Dehairs F, Beeckman H, Koedam N (2004) Annual cyclicity in high-resolution stable carbon and oxygen isotope ratios in the wood of the mangrove tree Rhizophora mucronata. Plant Cell Environ 27:1525-1536

Wang X-F, Yakir D, Avishai M (1998) Non-climatic variations in the oxygen isotopic compositions of plants. Glob Chang Biol 4:835849

Wernicke J, Grießinger J, Hochreuther P, Bräuning A (2015) Variability of summer humidity during the past 800 years on the eastern Tibetan Plateau inferred from 180 of tree-ring cellulose. Clim Past. https:// doi.org/10.5194/cp-11-327-2015

Wernicke J, Hochreuther P, Grießinger J, Zhu H, Wang L, Bräuning A (2016) Consequences of back-trajectory modeling for palaeoclimatic reconstructions derived from tree-ring stable oxygen isotopes on the monsoon influenced Tibetan Plateau. J Biometeorol. https://doi.org/10.1007/s00484-016-1292-y

Wieloch T, Helle G, Heinrich I, Voigt M, Schyma P (2011) A novel device for batch-wise isolation of $\alpha$-cellulose from small-amount 
wholewood samples. Dendrochronologia 19:115-117. https://doi. org/10.1016/j.dendro.2010.08.008

Zhu MF, Stott L, Buckley B, Yoshimura K, Ra K (2012) Indo-Pacific Warm Pool convection and ENSO since 1867 derived from Cambodian pine tree cellulose oxygen isotopes. J Geophys Res Atmos 117:D11307. https://doi.org/10.1029/2011JD017198
Ziaco E, Biondi F (2016) Tree growth, cambial phenology, and wood anatomy of limber pine at a Great Basin (USA) mountain observatory. Trees. https://doi.org/10.1007/s00468-016-1384-7

Publisher's note Springer Nature remains neutral with regard to jurisdictional claims in published maps and institutional affiliations. 